\title{
Anxiety and Suicidality Risk in Primary Care in General Population
}

\author{
${ }^{1 *}$ Maria Maniou, ${ }^{2}$ Christos Klisiaris, ${ }^{3}$ Sofia Zyga, ${ }^{4}$ Georgios Tsikritsakis, \\ ${ }^{4}$ Katerina Anathreptaki, ${ }^{5}$ Constantinos Togas, ${ }^{4}$ Maniola Naska
}

\author{
${ }^{1 *}$ Nurse, MSc, PhD(c), Organization of Social Solidarity and Education. Municipality of Archanes - Asterousia, \\ Technological Educational Institute of Crete - Nursing Department \\ ${ }^{2}$ Assistant Professor in Primary \& Home Care Nursing, MSc, PhD, Technological Educational Institute of \\ Crete - Nursing Department \\ ${ }^{3}$ Associate Professor, MSc, PhD, University of Peloponnese , Nursing Department \\ ${ }^{4}$ Nurse RN, Technological Educational Institute of Crete - Nursing Department \\ ${ }^{5}$ Social Worker-Psychologist, Msc, PhD(c), Corinth Prison, Korinth \\ Corresponding author: Maniou Maria \\ Technological Educational Institute of Crete, Nursing Department \\ mmaniou@hotmail.com
}

Introduction: Suicide is among the ten most common causes of death for all ages. Anxiety is a major risk factor for suicidal behavior in adolescents.

Aim: The main aim of this study was to examine anxiety and suicidality risk in patients in municipality of Heraklion in Crete.

Methodology: The sample of the study consisted of 203 individuals tested in the regular clinics of the University Hospital of Heraklion and in Health Center of Moires in 2016. For the data collection were used two questionnaires. The first involved the Scale of Stress Spielberger (Trait and State Anxiety) consisting of 40 graded scale and the Scale of suicidality Risk (RASS), consisting of 12 questions classified in a 4-point scale. They followed univariate correlations and evaluated indicators Odds Ratio of people with high vs. low grade RASS scale and also for the characteristics and Anxiety scores Spielberger by multiple regression analyses. The statistical analyses were performed using IBM SPSS 23.0 program.

Results: With higher risk suicidality were older individuals $(\mathrm{r}=0.201, \mathrm{p}<0.05)$, which are separated and live alone $(r=0.143, p<0.05)$ and / or lower educational level $(r=-0.245, p<0.05)$. Moreover, people with low family income were found with a significantly higher anxiety levels $(r=0.194, p<0.05)$, state anxiety $(r=0,174$, $\mathrm{p}<0.05)$ and trait anxiety $(\mathrm{r}=0.191, \mathrm{p}<0.05)$ as those with a lower level of education $(r=-0.278, \mathrm{p}<0,05)$. From the assessment of the indices odds ratio was significantly increased risk of suicidal behavior RASS by $16 \%$ (OR: 1,16, 95\% CI: 1.08 to 1.24) as varied increasing their state anxiety. Nine subjects (4.4\%) reported having attempted suicide at least once.

Conclusions: The suicidality seems to be influenced by existing conditions such as increasing age, the life situation or the low educational level and the state anxiety can be considered an important factor in suicidal behavior.

Keywords: suicidality, state anxiety, trait anxiety

Highlights

$>$ The suicidality seems to be influenced by existing conditions such as increasing age, the life situation or the low educational level. 
$>$ The state anxiety can be considered an important factor in suicidal behavior

$>$ People with low family income were found with a significantly higher anxiety levels, as those with a lower level of education.

$>$ From the assessment of the indices odds ratio was significantly increased risk of suicidal behavior RASS by $16 \%$ as varied increasing their state anxiety

\section{INTRODUCTION}

In many countries suicide is a major public health problem with ever-increasing trends. Suicide includes any behavior caused by the person himself and is carried out with the intent or expectation to end his / her life and involves passive acts caused by it or energetic [1].

Two main categories of suicidal behavior, suicide attacks, and complete suicides have been described in which the person's actions result in his death. One person may belong to these two categories [2,3,4].

Suicide is one of the most common causes of death for all ages. The factors that are mainly related to the high risk of suicide are biological factors, social-demographic factors, physical health problems and psychiatric morbidity. Risk factors such as race, age, marital status and religion-related suicides play an important role in suicide [5].

An adequate and documented assessment of the risk of suicide in an individual is not yet feasible. Correspondingly, the number of suicides in a given time period in a country is very difficult. Separation between suicide from killing by an accident or criminal act is difficult when there is no evidence (note, mental illness, previous attempts, warning) proving that killing is a criminal act, an accident or suicide [6].

Stress is the unpleasant emotional state that involves fear, feelings of tension or even horror in response to a source whose source is to a large extent unrecognizable or unknown. Anxiety is a common reaction that to some extent occurs in most people in the form of excessive response to mild stress-causing events [7]. Moreover, stressful life events play an important role in suicide [8].

When the person is in anxiety it is possible to experience some symptoms, which are categorized into psychological and physical symptoms. Psychotic symptoms include impotence, anxiety, feeling of indefinite fear and anxiety, anxiety, distraction, difficulty in concentrating, and a sense of reduced perception. In the physical symptoms belongs the problems of chest pain, dyspnoea, choking, knot feeling, stiffness, palpitations, anorexia, nausea, insomnia, fainting, kinetic anxiety, trembling, weakness, dizziness, sweating, frequency, cold hands, drooping tendency, abdominal pain, muscle tension headache and dry mouth [9].

Spielberger was the one who talked about the theory of anxiety in which he approached anxiety as trait anxiety, as a result of a situation and state anxiety as a characteristic of the personality. Trait anxiety is related to the subjective emotional state characterized by nervousness and tension. State anxiety is related to the person's predisposition to perceiving specific situations as threatening and reacting with stress to them disproportionate to the intensity or magnitude of the actual risk [10].

Stress is a major risk factor for suicidal behavior in teenagers and supports that doctors should consider the disease to evaluate and treat adults with suicidal behavior. Finally, Hill and colleagues argue that stress is a major risk factor for suicide-related behaviors in children and adolescents. There is limited evidence that the disease is an independent prognostic factor for suicidal behaviors in younger ages [11].

\section{RESEARCH PROBLEM}

A few studies have been done to examine the relationship between anxiety and suicide behaviour in Greece during period of economic crisis. Further research should be conducted on the issue as there is limited evidence. 


\section{OBJECTIVES}

The main aim of this study was to examine the relationship between suicidality risk and the existence of state and trait anxiety in the general population in municipality of Heraklion in Crete during the period of economic crisis.

\section{METHODS}

\section{Study Design}

The survey was conducted in a 3-month period (November 2016 - January 2017) in Heraklion of Crete. It is as descriptive study. The selection of the sample was done randomly Our random selection of subjects from primary care included all the patients that visited the regular clinics of the University Hospital of Heraklion and the Health Center of Moires All registered members were 203 people. Included criteria were a) age over 18 years $\mathrm{b}$ ) the information is provided only by the participant and c) no to have history of psychiatric illness. Three questionnaires were used to collect demographic information, information about suicides using the Risk Assessment Suicidality Scale Scale (RASS). Collection that concerns anxiety was performed using the Scale of Stress Spielberger (Trait and State Anxiety).

\section{The study questionnaire}

The first contains 6 multiple choice questions and attempts to capture the demographic characteristics of the participants. Also, for the data collection were used two questionnaires. The first involved the Scale of Stress Spielberger (Trait and State Anxiety) consisting of 40 graded scale and the Scale of Suicidality Risk (RASS), consisting of 12 questions classified in a 4-point scale. RASS is a self-report tool of suicidal risk behaviors which contains items relevant to intention, life, and history of suicide attempts rated on a 0-3 Likert-type scale (not at all to very much ).

They followed univariate correlations and evaluated indicators Odds Ratio of people with high vs. low grade RASS scale and also for the characteristics and Anxiety scores Spielberger by multiple regression analyses. Followed by univariate correlations, Chi Square and $\mathrm{X}^{2}$ markers were evaluated as well as using $\mathrm{T}$ Test.

\section{Ethics}

An ethical approval was provided by the $7^{\text {th }}$ Health Region of Crete and the Ethical Committee of the Technological and Educational Institute of Crete. Participants' anonymity was secured and an informed consent was provided before participation.

\section{Statistical Analysis}

The statistical analyses were performed using IBM SPSS 23.0 program. With the $\mathrm{x} 2$ test analysis were analyzed the distributions of the demographic characteristics of the patients (age, education level, gender) In addition, we used the average method where necessary (quantitative variables), the Chi Square test to find correlations between the variables, as well as the P-P plot reliability test (probability-probability plot or percent-percent plot).

\section{RESULTS}

A total of 203 patients were enrolled in the study from the regular clinics of the University Hospital of Heraklion and in Health Center of Moires. Table 1 shows the characteristics of the respondents. Most of them were male $(53,2 \%)$ aged $18-29$ years $(30,5 \%)$ aged $30-44$ years $(26,6)$ and $(27,1 \%)$ aged $45-59$. Finally, over the age of 60 are only the $15.8 \%$ of the respondents. Regarding the marital status, we notice that $46.3 \%$ are unmarried and $38.9 \%$ are married. 
Anxiety and Suicidality Risk in Primary Care in General Population

Table 1. Population characteristics

\begin{tabular}{|c|c|c|c|c|}
\hline \multicolumn{2}{|c|}{} & Frequency & Percent & Valid Percent \\
\hline \multirow{4}{*}{ Gender } & Male & 95 & 46,8 & 46,8 \\
\cline { 2 - 5 } & Female & 108 & 53,2 & 53,2 \\
\cline { 2 - 5 } Age & Total & 203 & 100,0 & 100,0 \\
\hline \multirow{4}{*}{} & $\mathbf{1 8 - 2 9}$ & 62 & 30,5 & 30,5 \\
\cline { 2 - 5 } & $\mathbf{3 0 - 4 4}$ & 54 & 26,6 & 26,6 \\
\cline { 2 - 5 } & $\mathbf{4 5 - 5 9}$ & 55 & 27,1 & 27,1 \\
\cline { 2 - 5 } & $\mathbf{6 0 +}$ & 32 & 15,8 & 15,8 \\
\cline { 2 - 5 } & Total & 203 & 100,0 & 100 \\
\hline
\end{tabular}

Furthermore, only $7.9 \%$ and $4.4 \%$ of the respondents are in dissociation or widowhood respectively. Finally, $2.5 \%$ said he lives alone. As far as the education of the participants is concerned, we observe that $11.3 \%$ are graduates of primary school and 55.1\% are graduates of secondary education. Finally, 25.1\% are graduates of higher education and only the $7.4 \%$ had a postgraduate or doctorate degrees. The $46.3 \%$ of the respondents are self-employed, $16.7 \%$ are civil servants and $10.3 \%$ are retired. In terms of personal income, $34.5 \%$ said their individual income was more than $4500 €$ opposed to 65\%). Moreover, $9500 €$ exceeds $60.6 \%$ of respondents (Table 2).

Table 2. Annual personal income $>$ 4,500 euros and >9,500 euros

\begin{tabular}{|c|c|c|c|c|}
\hline \multicolumn{2}{|c|}{} & Frequency & Percent & Valid Percent \\
\hline \multirow{2}{*}{\begin{tabular}{c} 
Annual personal $\begin{array}{c}\text { income } \\
>\mathbf{4 , 5 0 0} \text { euros }\end{array}$ \\
\cline { 2 - 5 }
\end{tabular}} & No & 70 & 34,5 & 34,7 \\
\hline Missing & Total System & 132 & 65,0 & 65,3 \\
\hline \multicolumn{2}{|c|}{ Total } & 1 & 99,5 & 100,0 \\
\hline
\end{tabular}

\begin{tabular}{|c|c|c|c|c|c|}
\hline \multirow{2}{*}{$\begin{array}{c}\text { Annual personal } \\
\text { income }\end{array}$} & No & 73 & 38,9 & 39,1 & 39,1 \\
\cline { 2 - 6 }$>\mathbf{9 , 5 0 0}$ euros & Yes & 123 & 60,6 & 60.9 & 100,0 \\
\cline { 2 - 6 } & & 202 & 99,5 & 100,0 & \\
\hline Missing & Total System & 1 &, 5 & & \\
\hline
\end{tabular}

The second part of the questionnaire used the Risk Assessment Suicidality Scale (RASS). The first question concerns the fear of the respondents about death and is formulated with the phrase "Are you afraid that you are going to die?" With $86.7 \%$ of the respondents responded negatively to the choice (not at all). While positive (quite and very much) answered the $13.3 \%$. The question of whether "you think it's a great thing you are alive now" is positive with the selection "enough" and "too much" the $77.8 \%$ and negatively "no" or "little" the 22 , $2 \%$ of respondents (Table 3 ).

Table 3. Questions concerns Risk Assessment Suicidality Scale (RASS)

\begin{tabular}{|l|l|l|l|l|}
\hline & & Frequency & Percent & Percent \\
\hline \multirow{3}{*}{$\begin{array}{l}\text { Thoughts to harm } \\
\text { himself }\end{array}$} & None & 189 & 93,1 & 93,1 \\
\cline { 2 - 6 } & Little & 12 & 5,9 & 5,9 \\
\cline { 2 - 6 } & Enough & 1 &, 5 &, 5 \\
\cline { 2 - 5 } & Too much & 1 &, 5 &, 5 \\
\hline
\end{tabular}

American Research Journal of Nursing 


\section{Anxiety and Suicidality Risk in Primary Care in General Population}

The indication that no one is worth living has had the $11.8 \%$ stating "enough " and "too much". The answer to the question whether "You think it's a great thing you're alive" answered positively with the choice "enough" and "too much" $77.8 \%$ and negatively with the choice "no" or "little" the $11.8 \%$ of the respondents. The indication that one is not worth living has had the $11.8 \%$ stating enough and too much. He thinks of doing evil to himself only the $1 \%$ of the respondents. To the question of whether they often think of committing suicide, if they found the opportunity, the $99 \%$ answered negatively. Respondents to the question of whether they think to end their lives, $93.6 \%$ answered a little. He plans to commit suicide but will not do it the $4.9 \%$ (Table 3).

\begin{tabular}{|c|r|c|c|c|c|}
\hline \multirow{2}{*}{$\begin{array}{c}\text { Fear } \\
\text { For }\end{array}$} & None & 110 & 54,2 & 54,2 & 54,2 \\
\cline { 2 - 6 } Death & Little & 66 & 32,5 & 32,5 & 86,7 \\
\cline { 2 - 6 } & Enough & 22 & 97,5 & 10,8 & 99,5 \\
\cline { 2 - 6 } & Too much & 5 & 2,5 & 2,5 & 100,0 \\
\hline
\end{tabular}

Tired of their lives declare the $21.7 \%$, while they do not agree with this view the $40.9 \%$, a little agree with this the $37.4 \%$ and quite the $16.3 \%$. He has hurt himself more than one time the $9.9 \%$ and never the $90.1 \%$ of the respondents. By computing the sum of the answers to the questionnaire, we observe that the total sum $<=$ $175 / 340$ has the $61.6 \%$ of the participants (Table 3 ).

\begin{tabular}{|c|c|c|c|c|c|}
\hline \multirow{2}{*}{$\begin{array}{c}\text { Deserves } \\
\text { someone }\end{array}$} & None & 132 & 65 & 65 & 65 \\
\cline { 2 - 6 } to live & Little & 47 & 23,2 & 23,2 & 88,2 \\
\cline { 2 - 6 } & Enough & 10 & 4,9 & 4,9 & 93,1 \\
\cline { 2 - 6 } & Too much & 14 & 6,9 & 6,9 & 100,0 \\
\hline
\end{tabular}

\begin{tabular}{|c|c|c|c|c|c|}
\hline \multirow{4}{*}{$\begin{array}{c}\text { Thoughts to } \\
\text { commit suicide }\end{array}$} & None & 188 & 92,6 & 92,6 & 92,6 \\
\cline { 2 - 6 } & Little & 13 & 6,4 & 6,4 & 99,0 \\
\cline { 2 - 6 } & Enough & 2 & 1,0 & 1,0 & 100,0 \\
\cline { 2 - 6 } & Total & 203 & 100,0 & 100,0 & \\
\hline \multirow{2}{*}{$\begin{array}{c}\text { Thoughts for } \\
\text { schedules to } \\
\text { end his life }\end{array}$} & None & 190 & 93,6 & 93,6 & 93,6 \\
\cline { 2 - 6 } & Little & 12 & 5,9 & 5,9 & 99,5 \\
\hline \multirow{3}{*}{$\begin{array}{c}\text { Thoughts for } \\
\text { suicide that are } \\
\text { not commited }\end{array}$} & Enough & 1 &, 5 &, 5 & 100,0 \\
\cline { 2 - 6 } & None & 183 & 90,1 & 90,1 & 90,1 \\
\cline { 2 - 6 } & Little & 10 & 4,9 & 4,9 & 95,1 \\
\hline \multirow{4}{*}{ Tired of his life } & Too much & 2 & 3,9 & 3,9 & 99,0 \\
\cline { 2 - 6 } & None & 83 & 4,0 & 1,0 & 100,0 \\
\cline { 2 - 6 } & Little & 76 & 37,4 & 40,9 & 40,9 \\
\cline { 2 - 6 } & Enough & 33 & 16,3 & 16,3 & 78,3 \\
\cline { 2 - 6 } & Too much & 11 & 5,4 & 5,4 & 100,0 \\
\hline
\end{tabular}

As we can see from the table of correlations, there is a significant relationship between gender and the degree of predisposition or risk of suicide. Women appear to be less prone than men. This observation is confirmed with a high statistical accuracy as the Chi Square indicator shows. Moreover, with statistical accuracy is confirmed that there is a positive dependence between age and the level of risk. More prone seems to be the younger ages with participants between 18- 44 gather higher rates (Table 4). 
Anxiety and Suicidality Risk in Primary Care in General Population

Table 4. Correlation between the risk of suicide and age

\begin{tabular}{|c|c|c|c|c|}
\hline \multirow{2}{*}{\multicolumn{2}{|c|}{ Count }} & \multicolumn{3}{|c|}{ Total risk comparison for suicide } \\
\hline & & 00 & $<=175 / 340$ & $>175 / 340$ \\
\hline \multirow{4}{*}{ Age } & $18-29$ & 1 & 39 & 22 \\
\hline & $30-44$ & 0 & 30 & 24 \\
\hline & $45-59$ & 0 & 42 & 13 \\
\hline & $60+$ & 0 & 14 & 18 \\
\hline \multicolumn{2}{|c|}{ Total } & 1 & 125 & 77 \\
\hline
\end{tabular}

The third part of the questionnaire used the STAI I-II scale to measure the disease in the population. This questionnaire is used to measure anxiety and the scale separates the disease as a condition (condition A) from the disease as a personality trait (A-Trait). In STAI I (A-State) measures the average of the participants were 44.5 while the median 44 indicates the absence of the effect of the extreme values. Furthermore, the average value of the observations describing the disease as a personality trait is 41.7 while the average 41 . The average of anxiety as a condition averages 43.63 for the self-employed with a variation of 7.8 and $45.29^{\prime}$ for the public servant (Table 5).

Table 5. Correlation between the mean of the anxiety as a characteristic of the personality and the scale of the risk assessment of suicides.

\begin{tabular}{|c|c|c|c|c|}
\hline \multicolumn{2}{|c|}{ Count } & \multicolumn{3}{c|}{ Total risk comparison for suicide } \\
\cline { 3 - 5 } \multicolumn{2}{|c|}{} &, 00 & $<=175 / 340$ & $>175 / 340$ \\
\hline \multirow{3}{*}{$\begin{array}{c}\text { Trait / State } \\
\text { anxiety }\end{array}$} & 1,00 & 0 & 36 & 4 \\
\cline { 2 - 5 } & 2,00 & 1 & 81 & 48 \\
\cline { 2 - 5 } & 3,00 & 0 & 8 & 25 \\
\hline \multicolumn{2}{|c|}{ Total } & 1 & 125 & 77 \\
\hline
\end{tabular}

It is noteworthy that there is no dependence between the family situation and the momentum towards suicide (Figure1).. The same absence of dependence is also observed between the existence of children or not. Due to the value of the ChiSquareSig2 index sided $=0.329$, there is no statistically significant dependence between the torque-dangers of suicide and the educational level (Table 6).. It is logical that the high values of the variable of fear for death appear in people with a high propensity to suicide. A high price and a high degree of agreement with this view also entails a high degree of risk in the final / overall score. Also, as expected, those who have been pleased with their lives and enjoy the way they spend time have less risk of suicide. It is also expected that the dependency between the risk and the tendency for suicide will be in the people that in the past have attempted to do bad to themselves as well as to the people who feel tired of their lives at this time by demonstrating in this way Some of the most important factors that affect human intent as well as confirming some important indicators. Moreover, the profession, the financial situation, and individual or family income are independent of the degree of fatigue from life.

By conducting test testing of two independent samples associated with age 18-29 and 45-59, we assume that the average value of the resistance index as a personality trait is equal, while the alternative is different. Since the sig value is less than 0.05 due to the value of sig 2 tail $>0.05$, we accept the zero hypothesis of the equivalence of the two independent samples. Finally, statistically significant dependencies appear between the mean of the disease as a characteristic of the personality and the suicide risk scale. Thus, the high values of one also imply high values of the other index that indicate the existence of a positive correlation. 
Anxiety and Suicidality Risk in Primary Care in General Population

Table 6. Correlation between the education level and the risk of suicide

\begin{tabular}{|c|c|c|c|c|}
\hline \multicolumn{2}{|c|}{ Count } & \multicolumn{3}{c|}{ Total risk comparison for suicide } \\
\cline { 2 - 5 } & $\mathbf{0 0}$ &, 00 & $<=175 / 340$ & $>175 / 340$ \\
\hline \multirow{4}{*}{$\begin{array}{c}\text { Education } \\
\text { level }\end{array}$} & Primary School & 0 & 1 & 0 \\
\cline { 2 - 5 } & Secondary School & 0 & 10 & 13 \\
\cline { 2 - 5 } & High School & 0 & 10 & 14 \\
\cline { 2 - 5 } & Higher School & 0 & 58 & 29 \\
\cline { 2 - 5 } & $\begin{array}{c}\text { Master of Science or } \\
\text { Doctor of Philosophy }\end{array}$ & 0 & 10 & 5 \\
\hline & Total & 1 & 124 & 77 \\
\hline
\end{tabular}

It is worth to notice that the value of the state anxiety is completely independent of demographic factors. Thus, the degree of experiencing the anxiety, either state or trait, is not affected by the marital status, sex or occupational status of respondents according to the Crosstabs Test and the Chi Square index. The only statistically significant dependence is observed between the anxiety as a temporary / general condition and the less stressed and anxious in the tertiary education graduates. The observation is confirmed by Chi square $<0$. Non-high family income was found with significantly higher levels of anxiety.

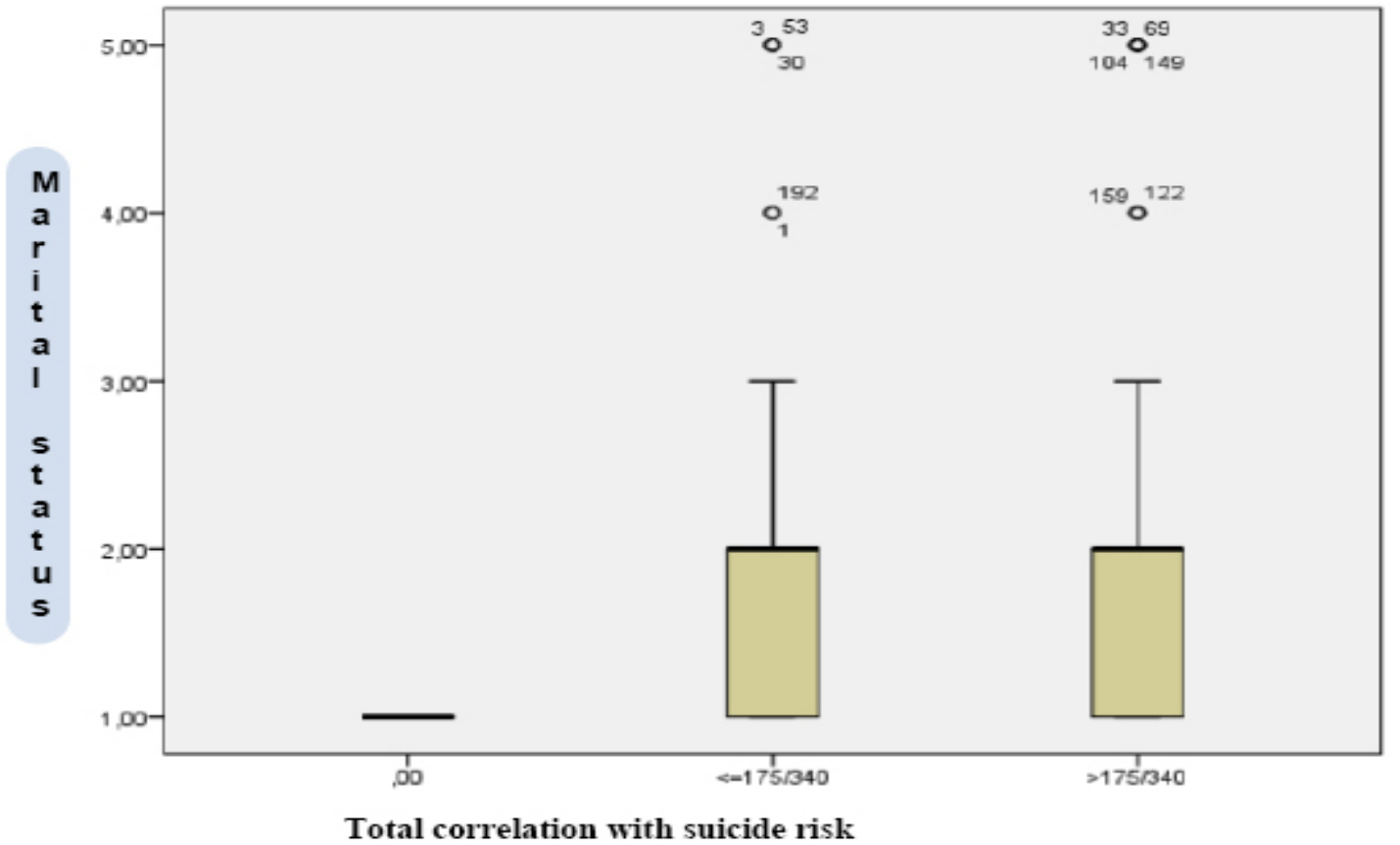

Fig1: Correlation between marital status and final suicide risk score

\section{DISCUSSION}

The results of the survey showed relatively high rates of anxiety indicators both as a condition and as a personality. More specifically, the average price was 44.5 and 41.7 compared to 37.34 set in an earlier survey. According to the National Study of Morbidity and Risk Factors (EMME), which took place in 2014, the Medical School in collaboration with all medical schools of Greek Universities and the Panteion University in a random sample of 5,000 people, 18 years old and over, It was found that the proportion of people with anxiety symptoms was $24 \%$, which is worrying Which is alarmingly high [12]. 
In the present study, non-high family income was found with significantly higher levels of anxiety $(r=0.194, p$ $<0.05)$, state $(r=0.174, p<0.05)$ and trait $(r=0.191, p<0,05)$ as well as those with a lower level of education $(\mathrm{r}=-0.278, \mathrm{p}<0.05)$. According to Moussuli (2016) the high levels of anxiety are related to various sociodemographic indicators such as low levels of education and low family income [13].

From the Odds Ratio was found a significant increase risk of suicide (RASS) 16\% (OR: 1.16, 95\% CI: 1.08-1.24) as their state anxiety increased. Thus, high values of one also result in high values of the other index, revealing the existence of a positive correlation. A study had found that anxiety is a major risk factor for suicidal behavior in adolescents and children, and they believe that physicians should get into account anxiety for the evaluation and treatment of adolescents with suicidal behavior [14]. According to Nock et al, anxiety is a significantly predict subsequent suicide attempts [15].

There is limited evidence that the disease is an independent predictor for suicidal behaviors. Studies have been made and examine the relationship between illness and suicidal behavior [16].

At a higher risk of suicide were found older people $(r=0.201, p<0.05)$, who are in a dissociation and living alone $(\mathrm{r}=0.143, \mathrm{p}<0.05)$ and / or lower educational level ( $\mathrm{r}=-0.245, \mathrm{P} \& \mathrm{lt} ; 0.05)$. According to a study, suicide rates increase with age, especially among men, and married women have the lowest rates of suicide. Extremely high suicidal signs were observed in widowed men aged 25-34 [17]. Another study carried out in 1967 showed that autotonicity rates are high in divorced and unmarried couples compared to married [18].

In addition, full independence appears to exist between the suicide risk indicator, the trait and state anxiety, the family or personal income and professional status. Studies demonstrating that there is a significant dependence between the suicide risk index, the trait and state anxiety, the family or personal income and occupational status have not been made before.

\section{CONCLUSIONS}

The results of the present study, especially when examined in relation to the theoretical background and the results of previous research found in the literature, show that anxiety can, as an etiological factor of suicide, perhaps be an over-simplification of the subject. Suicide appears to be affected by existing conditions such as age, living or low educational level, and permanent anxiety can be considered an important factor in suicidal behavior.

\section{RECOMMENDATIONS}

In addition, further research should be conducted on the issue as there is limited evidence that the disease is an independent prognostic factor for suicidal behaviors, and few studies have been done to examine the relationship between anxiety and suicide behavior

There is no doubt that further exploration of the subject will broaden the understanding of the theoretical relationships between suicide and anxiety. In order to gain a fuller understanding, interventions are needed in order to adequately manage the problems associated with anxiety and suicidal ideation as a whole. In addition, the evaluation of combined interventions such as psychological therapies, group psychotherapies combined with traditional therapeutic interventions are essential. The economic crisis is a great opportunity to protect services targeted at vulnerable populations, improve access to the mental health system, support the welfare state and promote interventions such as the reintegration of the unemployed and people with psychiatric problems, high risk. The training of primary health care physicians, the detection and treatment of depression and other common. Finally, the training of nurses and social workers working in Primary Care Units is considered very important for the detection of incidents with suicidal behavior with the use of tested tools

There is a prospect of continuing research through a pan-Hellenic program aimed at detecting suicidal behavior, depression and anxiety with the participation of community nurses in Primary Care Units and schools with school nurses as well as interim interventions with the creation of team psychotherapy teams. Finally evaluate the effects of psychotherapy on these incidents.

American Research Journal of Nursing

Page 8 


\section{REFERENCES}

1. De Leo D., Burgis S., Bertolote J.M, Kerkhof A.J.F.M. \& Bille-Brahe U. (2006). Definitions of Suicidal Behavior. Crisis 27(1), 4 -15.

2. Nock MK Prinstein MJ Clinical features and behavioral functions of adolescent self-mutilation J Abnorm Psychol, 2005, vol. 114 (pg. 140-66)

3. Nock MK, Kessler RC. Prevalence of and risk factors for suicide attempts versus suicide gestures: analysis of the National Comorbidity Survey, J Abnorm Psychol , 2006, vol. 115 (pg. 616-23) 35.

4. Nock MK, Joiner TE Jr, Gordon KH, et al. Non-suicidal self-injury among adolescents: diagnostic correlates and relation to suicide attempts, Psychiatry Res , 2006, vol. 144 (pg.65-72)

5. Maniou Saloustrou M, Zyga S, Pavlakis A, Anathreptaki AR (2017) Risk Factors for Suicide. Suicide in Primary Care Units and in Intensive Care Units. Nurse Care Open Acces J 2(5): 00048.

6. Jacobs MA, Anderson LS, Champagne E, Karush N, Richman SJ. \& Knapp PH .(1966) Orality, impulsivity, and cigarette smoking in men: further findings in support of a theory. J Nerv Ment Dis 143(3):207-19.

7. Manos N. (1997). Key elements of Clinical Psychiatry. Thessaloniki, University.Studio Press.

8. Maniou M, Tsikritsakis G, Zyga S, Pavlakis A and Klelsiaris. Stressful Life Events for Suicide. Suicide in Intensive Care Units and in Primary Care Units. JOJ Nurse Health Care. 2017; 2(1): 555580

9. Madianos M. (2003). Clinical Psychiatry. Athens: Kastaniotis

10. Spielberger C.D. (1966). Theory and research on anxiety. In C.D. Spielberger (Ed.), Anxiety and behavior (pp. 3-20). New York: Academic Press

11. Hill R. M., Castellanos D., \& Pettit, J. W. (2011). Suicide-related behaviors and anxiety in children and adolescents: A review. Clinical Psychology Review 31: 1133-1144

12. Mousouli P. (2016). Investigation of the impact of occupational burnout and illness on the mental health of police officers. Diploma thesis, Hellenic Open University.

13. Medical School of Athens. Press Release: The Health Situation in Greece in 2015:.Chronic Diseases - Access to the Health System - Prevention. Results of the study. .Athens.

14. Ohring R, Apter A, Ratzoni G, Weizman R, Tyano S. \& Plutchik R. (1966). State and trait anxiety in adolescent suicide attempts. J Am Acad Child Adolesc Psychiatry 35:154-157

15. Nock MK, Hwang I, Sampson NA, Kessler RC. Mental disorders, comorbidity and suicidal behavior: results from the National Comorbidity Survey Replication. Mol Psychiatry. 2010;15(8):868-876.

16. Hill R. M., Castellanos D., \& Pettit, J. W. (2011). Suicide-related behaviors and anxiety in children and adolescents: A review. Clinical Psychology Review 31: 1133-1144

17. Zaxarakis K, Madiakos M, Papadimitriou G \& Stefanis K. (2003). Epidemiology of suicide in Greece 1980-1997. Hellenic Medical Archives 20 (2), 191-199.

18. Pierce A. (1967) The Economic Cycle and the Social Suicide Rate. American Sociological Review 32(3):457-462.

Citation: Maria Maniou, Christos Klisiaris, Sofia Zyga, Georgios Tsikritsakis, Katerina Anathreptaki, Constantinos Togas, Maniola Naska, "Anxiety and Suicidality Risk in Primary Care in General Population". American Research Journal of Nursing. 2017; 3(1): 1-9.

Copyright (c) 2017 Maria Maniou, Christos Klisiaris, Sofia Zyga, Georgios Tsikritsakis, Katerina Anathreptaki, Constantinos Togas, Maniola Naska, This is an open access article distributed under the Creative Commons Attribution License, which permits unrestricted use, distribution, and reproduction in any medium, provided the original work is properly cited. 